- quake. The mountainous region around Amatrice is sparsely populated, but the final death toll may exceed that of more populated and urbanized L'Aquila.

Selvaggi seconds a public outcry over the failure of authorities to prioritize making old buildings more earthquake-resistant and notes that his team supplies earthquake maps to them. "We scientists have made a beautiful, detailed seismic hazard map, showing clearly the areas in greatest need of preventive measures," he says. "But public authorities don't take enough action."

The court case over the L'Aquila earthquake came about because a local amateur researcher claimed to have evidence of an imminent, large quake. Six scientists and one government official who had publicly dismissed the amateur's methods were accused of misinforming the public. Following an unprecedented trial, all

\section{EPICENTRE OF A QUAKE}

The earthquake is the strongest in Italy since the magnitude-6.3 event in 2009 near L'Aquila.

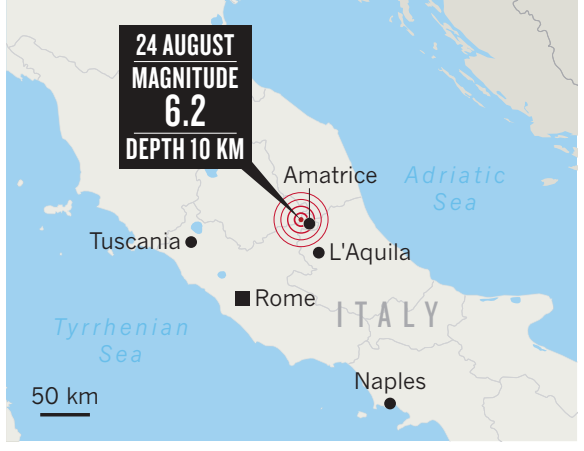

seven were given six-year jail sentences for manslaughter, but the scientists were cleared on appeal in 2014.
Computer scientist Paola Inverardi, who is rector of the university in L'Aquila, says the rebuilding of the university is nearly complete, and that research activities had resumed by 2012 . Science in the region has also benefited from supporting initiatives following the quake, she says. One of these is the Gran Sasso Science Institute, an international graduate school founded in 2012 to inject young intellectual life into L'Aquila. It has been so successful that in June it was awarded university status.

Unlike the earthquake in L'Aquila, which was preceded by frequent, mostly low-magnitude, tremors in the surrounding area, no seismic activity was recorded before the latest earthquake. "It came out of the blue, without the preceding tremors we experienced in 'our' earthquake," says Inverardi. L'Aquila itself experienced virtually no damage, but, she says, "psychologically we were all pushed back".

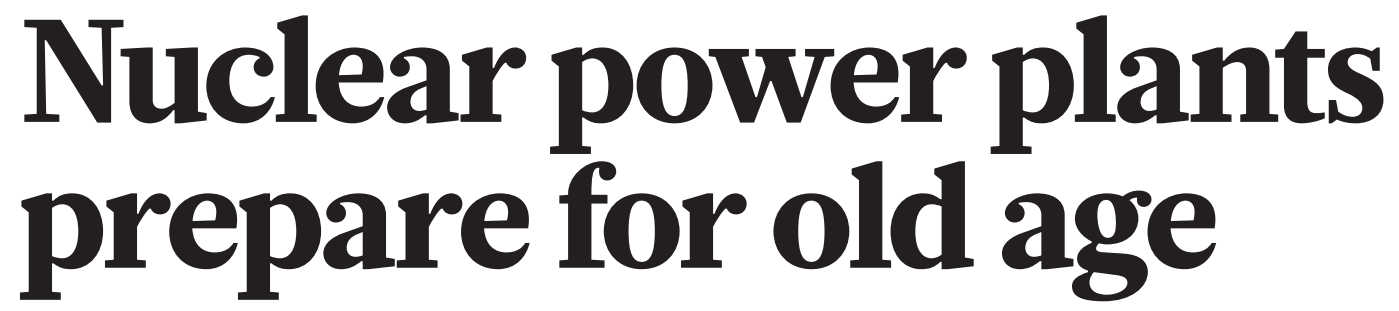

Efforts are afoot to keep the world's reactors running well past 2050.

\section{BY JEFF TOLLEFSON}

ophisticated inspections are helping to

$\mathrm{S}$ pick up defects in ageing nuclear power plants before they cause trouble. In March, ultrasonic tests identified signs of wear and tear in some of the stainless-steel bolts in the reactor core of the Indian Point power plant just north of New York City. Researchers at the Electric Power Research Institute (EPRI) in Palo Alto, California, are now analysing more than a dozen of the 5-centimetre-long bolts - which secure plates that help direct water through the radioactive core - to determine why they failed the inspection.

The analysis comes as the US Nuclear Regulatory Commission (NRC) considers whether to extend the life of Indian Point's two 40 -year-old reactors for 20 more years. Opponents of the plant, including the state of New York, cite the defective bolts, a transformer fire last year and environmental and safety concerns as evidence that the facility should close.

The plant's damaged bolts are just one example of the maintenance issues facing ageing nuclear reactors around the world. The

\title{
GOING, GOING, GONE
}

Nuclear power accounts for $20 \%$ of US electricity generation, but few new reactors are being built.

The following shows the total projected energy output of these plants under different licence-renewal plans.

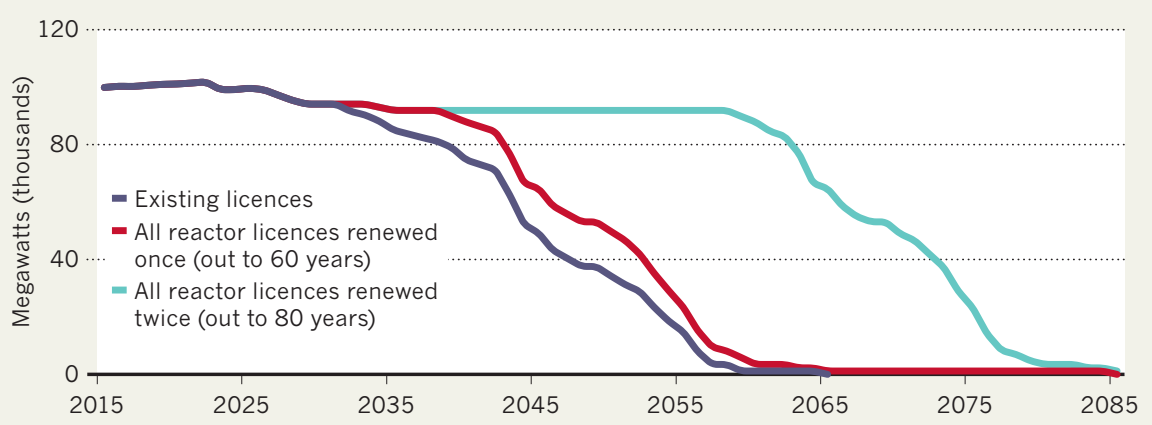

International Atomic Energy Agency and the NRC are developing management guidelines for these facilities, but the problem may be most acute for the United States, whose fleet of 99 reactors is the oldest and largest.

The NRC has renewed the licences of 81 US reactors still in operation for another 20 years. And it presented safety guidelines in December for utilities considering renewing their licences for another 20 years. But concerns remain about the effects of time on facilities that could be in operation for 80 years (see ‘Going, going, gone’).

Former NRC chair Allison Macfarlane says that the industry has been struggling economically in the face of cheap natural gas, and that many nuclear power companies are investing the bare minimum when it comes to maintenance and upgrades. She would rather see a transition to newer - and safer - reactor designs than attempts to push old ones to their limits.

\section{EXTENDING LIFETIMES}

Kurt Edsinger, director of materials at the EPRI, and his team will run a battery of tests on some of the Indian Point bolts to examine fractures and assess the strength of the material. They will also analyse the effects of roughly four decades of neutron bombardment on the crystalline structure of the steel in the bolts. 


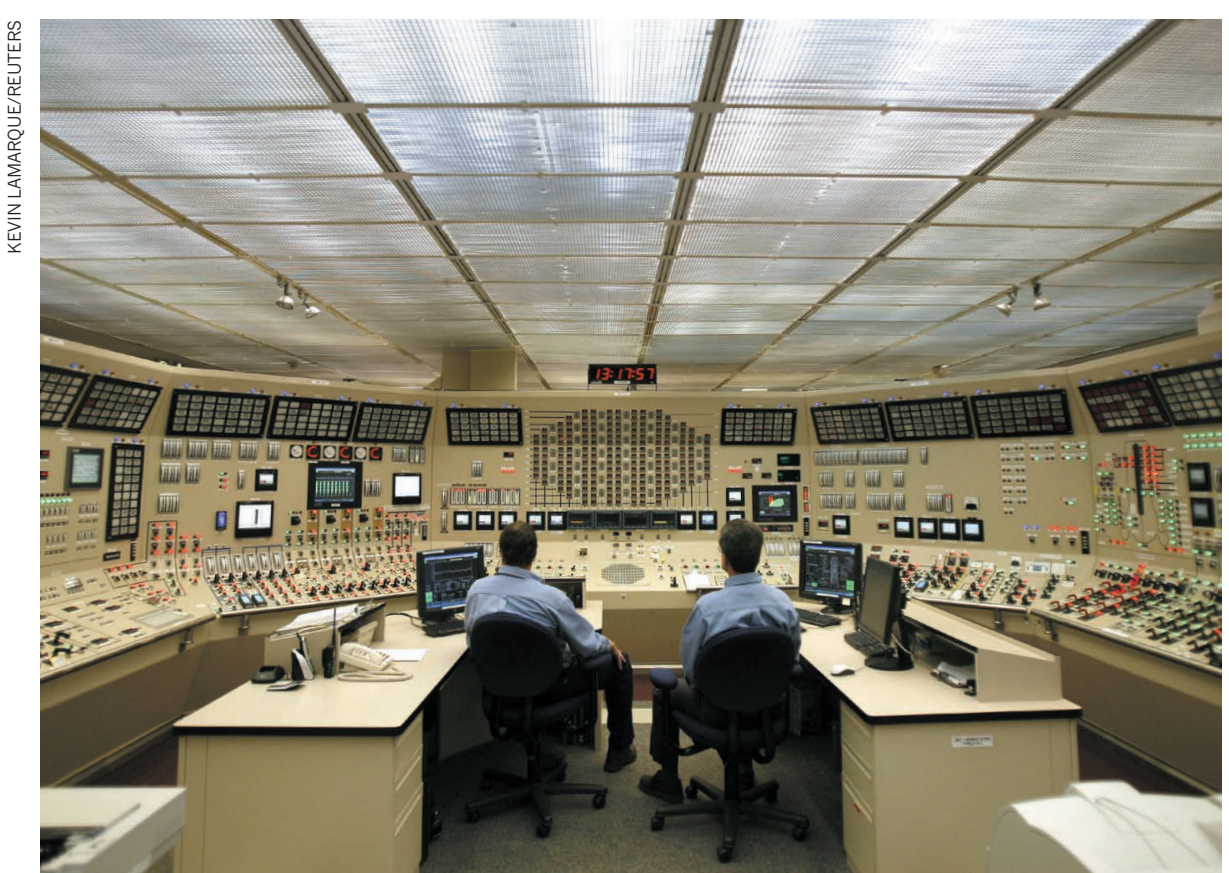

Many US nuclear-reactor facilities are old. The Browns Ferry plant in Athens, Alabama, opened in 1974.

The study is part of a larger effort by the EPRI and the US Department of Energy to inform the industry and regulators around the world about the risks regarding ageing materials and components as nuclear power plants come up for further licence renewals.

"So far, there have been no generic showstoppers identified that would preclude a second licence renewal," says Kathryn McCarthy, technical director of the energy department's Light Water Reactor Sustainability Program.

With few new reactors coming on line around the world, the longevity of existing facilities could have huge implications for the global climate.

Nuclear plants currently provide $20 \%$ of the United States' electricity - and more than half of its low-carbon power. At the global level, only hydropower provides more low-carbon
"If you maintain them and replace parts, there is no reason why nuclear plants can't run a very long time." power, at roughly $16 \%$ of total electricity produced, compared with nearly $11 \%$ for nuclear.

"If you maintain them and replace parts, there is no reason why nuclear plants can't run a very long time, which is great news from a climate perspective," says Michael Shellenberger, president of the Environmental Progress advocacy group in Berkeley, California.

Others are less sanguine. Important questions remain regarding the durability of parts that inspectors cannot see, such as underground power cables, as well as about how materials age, says Macfarlane.

Of particular concern are the concrete containment structures and steel pressure vessels at the heart of reactors, as well as the kilometres of wires that snake through the plants. Researchers are now analysing the long-term effects of intense heat and neutron bombardment on a plant's crucial materials down to the atomic level.

In some cases, scientists conduct accelerated-ageing experiments, in which materials are intensely irradiated to simulate 80 years of activity inside a reactor. That information can then be plugged into models that project degradation.

\section{EARLY WARNING}

The NRC's licence-renewal process focuses on crucial infrastructure that might not be part of regular maintenance programmes. The goal is to create an inspection system that detects defects before they become a problem, says Allen Hiser, a senior technical adviser in the NRC division that handles licence renewals.

NRC officials say this is what happened at Indian Point; similar bolt defects were discovered in 1988 at a nuclear reactor in France, and the agency established inspection requirements to detect such issues in the future.

But that is not the whole story, says Dave Lochbaum, head of the nuclear-safety project at the Union of Concerned Scientists advocacy group in Cambridge, Massachusetts. The ultrasonic inspection that identified the damaged bolts at Indian Point - a technique that is now mandatory - came about only after the state of New York challenged the adequacy of visual inspections nearly a decade ago, he says.

Macfarlane remains sceptical. If the licences for current US plants are renewed for a second time, the facilities will live to be 80 years old, with nearly 100 -year-old designs, she says. "We would be much better off with some of the newer reactors." 